\title{
SCIDiC
}

International Journal of Dentistry and Oral Science (IJDOS)

ISSN: 2377-8075

\section{Effect Of Social Relationships On Oralhealth Among Older Individuals}

Research Article

T Sai Pravallika ${ }^{1}$, Nandini Biradar ${ }^{2 *}$, Ganesh Kulkarni ${ }^{3}$, Hariprasad Gone ${ }^{4}$

${ }^{1}$ Senior Resident, Department of Public Health Dentistry, Government Dental College and Hospital, Afzalgunj, Hyderabad,Telangana, India.

${ }^{2}$ Associate professor, Department of Dentistry, Bidar Institute of Medical Sciences, BIDAR, Karnataka, India.

${ }^{3}$ Reader, Department of Oral Pathology, Malla Reddy Institute of Dental Sciences, Jeedimetla, Hyderabad-500055,Telangana, India.

${ }^{4}$ Senior Lecturer, Department of Public Health Dentistry, Malla Reddy Institute of Dental Sciences, Jeedimetla, Hyderabad,Telangana, India.

\section{Abstract}

Introduction: The favorable influence of social relations on health is widely recognized in gerontologic, epidemiologic, and public health research. The function of social relations is defined as the interpersonal interactions within the structure of the social relations. It is seen that social relations have long been implicated as a causal factor of general health and limited literature exists on associations between social relations and oral health.

Objectives: The objective of the study was to analyze whether social relations influence oral health among adults aged 60 and older.

Methods: The study was conducted for a duration of one month. All the adults aged 60 and older attending the outpatient department of Sri Sai college of dental surgery were included in the study. A questionnaire which comprised questions related to social relations and dentition status was prepared based on the previous literature.

Results: A total of 161 elderly individuals with a mean age of $65.3 \pm 5.3$ years participated in the study. Only $8.7 \%$ of the population were living alone. Majority i.e. $62 \%$ of them were not accompanied by any of their family members on visiting a hospital. Mean DMFT of individuals who were not satisfied with their social contacts was found to be $16.86 \pm 11.92$.

Conclusion: Overall there was no significant association observed between social relationship and oral health status of elderly individuals. More longitudinal studies aimed at a larger population must be conducted to achieve an appropriate result.

Keywords: Social Relationship; Oral Health Status; Older Individuals.

\section{Introduction}

Scientists have long noted an association between social relationships and health.There is an inverse association between social relationships and psychological ill health, cognitive disability, cardiovascular disease, and mortality. Different mechanisms have been suggested to explain the influence of social relationships on health [1]. First, social relationships can affect health directly. Individuals belonging to social networks are more likely to follow health-enhancing behaviors and to have higher self-esteem hence, have better health. Second, social relationships may buffer the negative effects of stressors on health, as individuals with better social support have wider access to information, financial resources, and emotional resources that help mitigate consequences of stressful events and alter their behaviors and coping with diseases and risk factors. Furthermore, the association betweensocial relationships and health may be confounded by broader determinants such as socioeconomic position, social relationships and their network [2].

From the beginning to the end of the 20th century, human life expectancy at birth has almost doubled in developed countries with the increased life expectancy and so the percentage of elderly people is also increasing worldwide, which is considerable now. Projections indicate that by the year 2020, there will be 470 million people aged 65 and above in developing countries, more than double the number in developed countries [3].

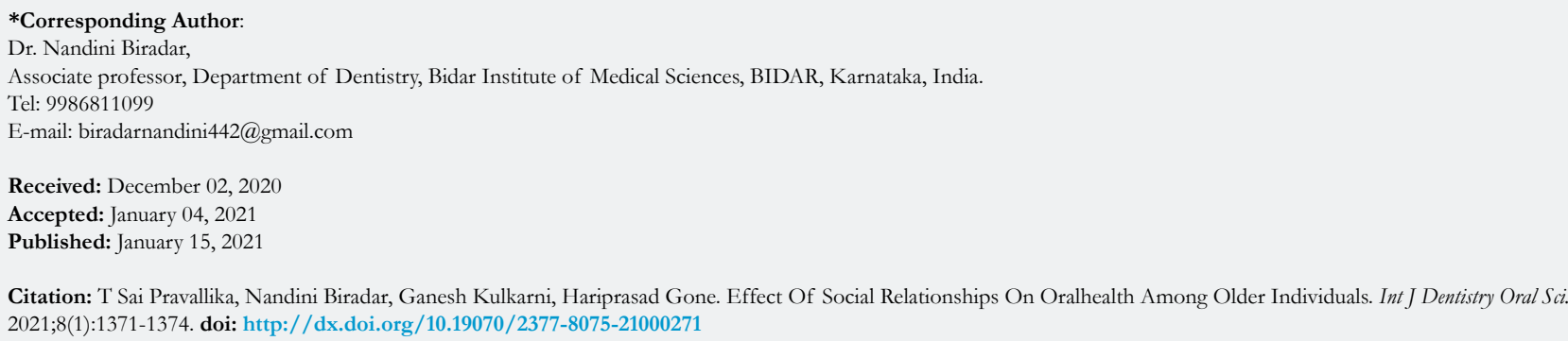

Citation: T Sai Pravallika, Nandini Biradar, Ganesh Kulkarni, Hariprasad Gone. Effect Of Social Relationships On Oralhealth Among Older Individuals. Int J Dentistry Oral Sci. 2021;8(1):1371-1374. doi: http://dx.doi.org/10.19070/2377-8075-21000271

Copyright: Nandini Biradar ${ }^{\circ}$ 2021. This is an open-access article distributed under the terms of the Creative Commons Attribution License, which permits unrestricted use, distribution and reproduction in any medium, provided the original author and source are credited. 
United Nations standard had not formulated a criterion, but the UN agreed a cutoff of $60+$ years when referring to the elderly population [4]. In India, the elderly account for $7 \%$ of the total population, of which two-thirds live in villages and nearly half of them in poor conditions. Urbanization, nuclearisation of family, migration, and dual career families are predisposing as social problems to the older population in India [5]. Ageing is inherent to the human being and makes an individual weak, hard of hearing, partially blind and immobile, the aged seldom move out or approach for help and consultation.

Due to the above problems, the aged feel lonely and this has detrimental influence on health of the aged and also, loneliness leads to progressive spontaneous reduction of daily milieu and social requirements, as well as an impression of dependence that cannot be easily overcome. This as a whole has an effect on the psychological well-being of elderly individuals which can be linked to their oral health.

Few studies done on oral health have shown that social relationships provide a protective effect on oral health. Studies on children and adolescents have indicated that social cohesion has beneficial effects on dental caries experience [6]. Among older adults, poorer social support was associated with having fewer functioning teeth and anterior tooth spaces [7], fewer teeth and worse dental behaviors [8], and more periodontal attachment loss [9]. A study done in Britain has shown that social support was associated with oral health status and oral health behavior of older individuals [8].

However there is less literature available on the social relationship and its effect on oral health of the elderly individuals in Indian context. Such analyses would provide a picture of the pattern of associations and identify which aspects of oral health, if any, are influenced by social relationships. This study evaluated the associations between social relationship and different oral health outcomes (edentulism, decayed teeth, sound or filled teeth, and oral healthbehaviour) among adults aged 60 years or older attending the outpatient department of Sri Sai College of Dental Surgery.

The objectives were to assess whether there are significant associations between social relationships and different oral health outcomes and whether these associations were explained by demographic, socioeconomic, behavioral factors, and physical health.

\section{Materials and Methods}

A cross sectional study was conducted among 161 elderly individuals aged 60 and older attending the out patient department of Sri Sai College of Dental Surgery. A pilot study was conducted prior to the instigation of the study to check the feasibility of the study and to validate the questionnaire. All the individuals who were aged 60 and older attending the outpatient department for one month and willing to participate in the study were considered. Informed consent was taken verbally prior to the study from every individual. Ethical approval for this research was obtained from the institutional ethical review board.

Questionnaire was developed based on previous literature. The questionnaire consisted of closed ended questions and obtained information regarding demographic and physical health variables; and information on social integration, social networks and relational content. Initially it was prepared in the English language and later converted to vernacular languagetelugu (reliability Cronbach's alpha 0.7). The clinical oral examination was comprehensive and was conducted by trained and calibrated dentist (intraexaminer reliability kappa value 0.8 ) in the department of Public Health Dentistry. Dentition status according to WHO 2013 was recorded via a visual clinical examination with the aid of a mouth mirror and a CPI probe in the department of public health dentistry. Information from the individuals was collected by interview method as most of the individuals were illiterate and was not in a position to read and answer the questionnaire. Bivariate analysis using Mann Whitney $U$ test was performed to test the association between social relationship and oral health status.

\section{Results}

A total of 161 elderly individuals were studied, mean age of them was found to be $65.3 \pm 5.3$ years, table 1 shows the demographic details of the participants where majority $59 \%$ of the elderly individuals were males and remaining $41 \%$ of them were females. $42.9 \%$ were farmers or were in to business, followed by $33.5 \%$ who were unemployed. Most of them $(61.5 \%)$ were illiterates and $67.7 \%$ of them were found to be living with their spouse. It was interesting to know that $36 \%$ of the elderly individuals have never visited a dental hospital prior to the present visit.

Table 2 shows the relationship between factors relating to social relationship and various oral health outcomes. Bivariate analysis did not show any association between social relationship and oral health status factors of elderly individuals. It was seen that people living alone were having higher number of mean decayed teeth i.e. 2.21 than the elderly individuals who lived with any of their family members 1.32. Individuals who were deprived of emotional support were having a high mean DMFT of 16.58 whereas individuals with financial support showed high mean DMFT of 16.80. The mean of the total teeth present was seen to be high for individuals who were having emotional support i.e. 17.41 and not having financial support i.e. 17.46. It was seen that higher number of individuals $13 \%$ who were not supported financially were wearing prosthesis.

\section{Discussion}

This study represents one of the fewest attempts to explore an association between social relationship and oral health of elderly individuals. The social support through family members is unique in the social relationship and people often expect different types of support from their family members towards the use of health services [10].

The number of decayed teeth is clinical indicator of current oral disease, thereby presenting negative oral health outcomes. The mean number of teeth affected with decay in the present study were more in individuals living alone than those who lived with others. Social relations are frequently associated with better preventive or therapeutic medical regimens. With regard to oral health, significant others such as spouse may be particularly important as models of appropriate behavior and normative influences on regular maintenance of teeth. 
Table 1. Demographic details.

\begin{tabular}{|c|c|c|}
\hline \multicolumn{2}{|c|}{ Demographic details } & Percentage \\
\hline \multirow{2}{*}{ Gender } & Male & 59 \\
\hline & Female & 41 \\
\hline \multirow{6}{*}{ Occupation } & Unemployed & 33.5 \\
\hline & Unskilled & 14.9 \\
\hline & Skilled & 2.5 \\
\hline & Business & 42.9 \\
\hline & Semi profession & 3.1 \\
\hline & Profession & 3.1 \\
\hline \multirow{6}{*}{ Education status } & Illiterate & 61.5 \\
\hline & Primary & 1.9 \\
\hline & Middle & 19.9 \\
\hline & High & 8.1 \\
\hline & Intermediate & 3.1 \\
\hline & Undergraduate & 5.6 \\
\hline \multirow{3}{*}{ Marital status } & Married & 67.7 \\
\hline & Widowed & 31.1 \\
\hline & Single & 1.2 \\
\hline \multirow{5}{*}{ Medical condition } & No medical history & 66.5 \\
\hline & Hypertension & 22.4 \\
\hline & Diabetes & 7.5 \\
\hline & Asthma & 2.5 \\
\hline & Others & 1.2 \\
\hline
\end{tabular}

Table 2. Social relationships and oral health outcomes.

\begin{tabular}{|c|c|c|c|c|c|c|c|c|}
\hline & & & \multirow{2}{*}{$\begin{array}{c}\text { DT } \\
\text { Mean }\end{array}$} & \multirow{2}{*}{$\begin{array}{l}\text { DMFT } \\
\text { Mean }\end{array}$} & \multirow{2}{*}{$\begin{array}{c}\text { TEEH } \\
\text { PRESENT }\end{array}$} & \multicolumn{2}{|c|}{ PROSTHESIS } & \multirow{2}{*}{$P$ value } \\
\hline & & & & & & absent & present & \\
\hline \multirow{2}{*}{ Are you living? } & Alone & 8.7 & $10.93 \pm 9.71$ & $10.93 \pm 9.71$ & $2.21 \pm 2.33$ & $92.80 \%$ & $7.20 \%$ & NS \\
\hline & Someone & 91.3 & $16.70 \pm 11.91$ & $16.70 \pm 11.91$ & $1.32 \pm 2.08$ & $87.70 \%$ & $12.30 \%$ & NS \\
\hline \multirow{2}{*}{$\begin{array}{l}\text { Satisfied with social con- } \\
\text { tacts }\end{array}$} & Yes & 72.7 & $15.95 \pm 11.83$ & $15.95 \pm 11.83$ & $1.50 \pm 2.21$ & $87.20 \%$ & $12.80 \%$ & NS \\
\hline & $\mathrm{No}$ & 27.3 & $16.86 \pm 11.92$ & $16.86 \pm 11.92$ & $1.14 \pm 1.82$ & $90.90 \%$ & $9.10 \%$ & NS \\
\hline \multirow{2}{*}{$\begin{array}{c}\text { Did anyone accompany } \\
\text { you to the hospital }\end{array}$} & Yes & 37.9 & $15.25 \pm 11.46$ & $15.25 \pm 11.46$ & $1.66 \pm 2.33$ & $91.80 \%$ & $8.20 \%$ & NS \\
\hline & No & 62.1 & $16.78 \pm 12.06$ & $16.78 \pm 12.06$ & $1.24 \pm 1.96$ & $86 \%$ & $14 \%$ & NS \\
\hline \multirow{2}{*}{$\begin{array}{l}\text { Do you have anyone to } \\
\text { provide emotional support }\end{array}$} & Yes & 83.9 & $16.13 \pm 11.78$ & $16.13 \pm 11.78$ & $1.41 \pm 2.17$ & $88.80 \%$ & $11.20 \%$ & NS \\
\hline & No & 16.1 & $16.58 \pm 12.27$ & $16.58 \pm 12.27$ & $1.31 \pm 1.81$ & $88.40 \%$ & $11.60 \%$ & NS \\
\hline \multirow{2}{*}{$\begin{array}{l}\text { Do you have anyone to } \\
\text { provide financial support }\end{array}$} & Yes & 37.9 & $16.80 \pm 11.81$ & $16.80 \pm 11.81$ & $1.75 \pm 2.41$ & $90.10 \%$ & $0.90 \%$ & NS \\
\hline & No & 62.1 & $15.83 \pm 11.87$ & $15.83 \pm 11.87$ & $1.18 \pm 1.88$ & $87 \%$ & $13 \%$ & NS \\
\hline
\end{tabular}

$\mathrm{P}$ value $\leq 0.05$

DMFT of individuals who were accompanied by an attendant was found to be less when compared to the individuals who were not accompanied by anyone. This finding was in line with a study done by Takeuchi $\mathrm{K}$ et al., [11] done on Japanese older adults where better dental health status in the groups with higher social participation rates was observed. Lack of social participation can have negative effects on health which can cause psychological stress, which in turn adversely affects dental health. Psychological stress may cause elevated protein concentration in saliva and as salivary proteins interact with oral microorganisms, a potential link between psychological stress and oral health is possible [12,
13].

Being edentate represents a broad clinical oral health measure in this age group reflecting a lifetime history of dental diseases but also influenced by access to and use of dental services. The total number of teeth present in the study was found to be higher 23.26 \pm 10.72 among individuals who live alone. This was in contrary with a study done by Treasure et al., [14] done on UK adults who were single and were more likely to have lost all their natural teeth.

Most of the individuals who were alone have never visited a 
dentist when compared to the individual who were living with someone. These results support the finding of a study done by McGrath et al., [8] where living alone was associated with poorer oral health and less frequent dental attendance. Special attention should be drawn to the reason that being married or living with a partner has a protective effect on the oral health motivating the individuals towards seeking dental care.

It was observed that few individuals with financial support wearing prosthesis than individuals without financial support. This may be due to the fact that most of them might not feel comfortable in spending money supported by others as that of individuals who earn on their own. At this age an impression of dependence cannot be overcome easily.

\section{Conclusion}

Over all there was no association observed between social relationship and oral health status of elderly individuals among the study population. This can be accounted to the fact of joint family support system which is most commonly evident in the rural population where families live together.As the study done was in a hospital setting on a small sample this might not have reflected the association appropriately and a need for more longitudinal studies on a national sample is recommended.

\section{References}

[1]. Cohen S, Gottlieb BH, Underwood LG. Social relationships and health. In: Cohen S, Gottlieb BH, Underwood LG, editors. Measuring and Intervening in Social Support. New York, NY: Oxford University Press; 2000:3Y25.

[2]. Locker D, Clarke M, Payne B. Self-perceived oral health status, psychologi- cal well-being, and life satisfaction in an older adult population. J Dent Res. 2000 Apr;79(4):970-5. PubmedPMID: 10831100.

[3]. United Nation Population Assessment. In: WHO TechnicalReport Series 853. Geneva; 1992. p. 4

[4]. Available from: http://www.who.int/healthinfo/survey/ageingdefnolder/en/ index.html. [last accessed on 2008 Jan 15].

[5]. Lena A, Ashok K, Padma M, Kamath V, Kamath A. Health and social problems of the elderly: a cross sectional study in Udupi taluk Karnataka. Indian J Community Med 2009;34(2):131-134.Pubmed PMID: 19966960.

[6]. Aida J, Ando Y, Oosaka M, Niimi K, Morita M. Contributions ofsocial context to inequality in dental caries: a multilevel analysis offapanese 3-year-old children. Community Dent Oral Epidemiol 2008; 36:149-56.PubmedPMID: 18333879.

[7]. Hanson BS, Liedberg B, Owall B. Social network, social support anddental status in elderly Swedish men. Community Dent Oral Epidemiol 1994;22:331-7.Pubmed PMID: 7813188.

[8]. McGrath C, Bedi R. Influences of social support on the oral health of olderpeople in Britain. J Oral Rehabil 2002;29:918-22.Pubmed PMID: 12421323.

[9]. Sabbah W, Tsakos G, Chandola T, Newton T, Kawachi I, Sheiham A, MarmotMG, Watt RG. The relationship between social network, social supportand periodontal disease among older Americans. J ClinPeriodontol 2011;38:547-52.PubmedPMID: 21362014.

[10]. Gallo F. The effects of social support networks on the health of the elderly. Soc Work Health Care. 1982;8(2):65-74.Pubmed PMID: 7170671.

[11]. Takeuchi K, Aida J, Kondo K, Osaka K. social participation and dental health status among older Japanese adults : a population based cross sectional study. Plos one. 2013; 8(4): 1-6.Pubmed PMID: 23613921.

[12]. Van Tilburg T. Losing and gaining in old age: changes in personal network size and social support in a four year longitudinal study. J Gerontol 1998;52:S313-23.Pubmed PMID: 9826973.

[13]. Avlund K, Due P, Holstein BE, Sonn U, Laukkanen P. Changes in household composition as determinant of changes in functional ability among old men and women. Aging ClinExp Res 2002;14S:65-74.Pubmed PMID: 12475135.

[14]. Treasure E, Kelly M, Nuttall N, Nunn J, Bradnock G, White D. Factors associated with oral health: a multivariate analysis of results from the 1998 Adult Dental HealthSurvey. British Dental Journal. 2001; 190(2):60-68. Pubmed PMID:11213337. 